\title{
Análise dialélica e uso de marcadores microssatélites na avaliação de cultivares de trigo
}

\author{
Diallel analysis and use of microsatellite markers for the evaluation of wheat cultivars
}

\author{
Cristiane Zocatelli Ribeiro ${ }^{\mathrm{F}}$ Ronald José Barth Pinto ${ }^{\mathrm{I}}$ Francisco de Assis Franco ${ }^{\mathrm{II}}$ Volmir Sérgio \\ Marchioro $^{\text {II }}$ Ivan Schuster ${ }^{\text {II }}$ Elisa Serra Negra Vieira ${ }^{\text {II }}$
}

\section{RESUMO}

Foi avaliada a capacidade combinatória de oito cultivares de trigo, por meio de um esquema dialélico analisado segundo o modelo quatro da metodologia de Griffing. Paralelamente, foi realizada uma análise de dissimilaridade com marcadores SSR, a partir de estimativas de distância genética baseadas em pedigree. Oito características foram avaliadas num experimento delineado em blocos ao acaso, com duas repetiçoes. $O$ agrupamento das cultivares a partir das distâncias genéticas foi efetuado com os métodos UPGMA $e$ Tocher. Ficou evidenciada a variabilidade entre os genótipos de trigo. As cultivares 'CD 108', 'CD 0542'e 'CD 104' apresentaram grande capacidade geral de combinação para vários caracteres. Os maiores valores de capacidade específica de combinação foram detectados nos híbridos mais heterozigotos, formados pelo cruzamento de parentais integrantes de grupos diferentes. Os agrupamentos indicados pelo pedigree não coincidiram com os indicados a partir dos marcadores moleculares. As distâncias dos marcadores SSR provavelmente refletem melhor as relações entre as cultivares de trigo do que as distâncias medidas com base na genealogia. A falta de associação entre os padrões de agrupamento foi provavelmente devida às propriedades intrínsecas de cada forma de estimação das distâncias genéticas, as quais podem modificar a interpretação e a distribuição da variabilidade genética entre os genótipos avaliados.

Palavras-chave: Triticum aestivum, coeficiente de parentesco, cruzamentos dialélicos, dissimilaridade.

\section{ABSTRACT}

The combining ability of eight wheat varieties was evaluated according to the fourth model of the Griffing's diallelic methodology. Studies on genetic dissimilarity based on microsatellite markers and genetic distance among genotypes from pedigree data were also performed. The experiment was carried out in a randomized block design with two replications. Eight traits were evaluated in the diallel. Genotypes were grouped according to the UPGMA and Tocher methods. Genetic variability among genotypes was evident. Varieties 'CD 108', 'CD 0542' and 'CD 104' were those who showed high values for general combining ability in several traits. Since the effects of specific combining ability were more important in those particularly heterozygous combinations obtained from varieties allocated in different clusters, field and molecular results coincided in a certain way. There was no a good coincidence between the dendrogram based on parentage coefficient and the one based on microssatellite markers. The very small association between standards of grouping was probably related to the intrinsic properties of each way of estimating the genetic distance, which can modify the interpretation and the distribution of the genetic variability in the evaluated genotypes.

Key words: Triticum aestivum, parentage coefficient, diallel crosses, dissimilarity grouping.

\section{INTRODUÇÃO}

O aumento da produção de trigo no Brasil requer o emprego de cultivares bem adaptadas aos diversos ambientes (CAIERÃO et al., 2006). No melhoramento, o êxito dos cruzamentos depende da magnitude da segregação e da forma de herança das características agronômicas (GANDIN et al., 1983), associados à redução do número de parentais pela seleção de cultivares divergentes com alta capacidade combinatória (VIEIRA et al., 2005).

'Programa de Pós-graduação em Genética e Melhoramento, Universidade Estadual de Maringá (UEM). Av Colombo, 5790, 87020900, Maringá, PR, Brasil. E-mail: cris.zocatelli@gmail.com. *Autor para correspondência.

"Cooperativa Central de Pesquisa Agrícola (COODETEC), Cascavel, PR, Brasil. 
As informações fenotípicas, morfológicas e agronômicas (CRUZ et al., 2004), bem como ferramentas importantes provenientes de dados genealógicos (ALMANZA-PINZÓN et al., 2003) e moleculares (FRANCO et al., 2001; FONSECA et al., 2006; VIEIRA et al., 2007) permitem a identificação e quantificação da divergência genética. As informações sobre a genealogia dos parentais permitem calcular a estimativa das distâncias genéticas por meio do coeficiente de parentesco. BERTAN et al. (2007) ressaltaram que a análise da variabilidade genética, por meio das distâncias genéticas e morfológicas, pode ser fundamental para a eficiência do programa de melhoramento.

No presente trabalho, a metodologia dialélica foi empregada na quantificação da capacidade combinatória, com a perspectiva de contribuir para a escolha de genótipos superiores em blocos de cruzamentos. Foi verificada a correspondência entre as estimativas de capacidade combinatória, obtidas do dialelo, e as distâncias genéticas dos parentais, estimadas por informações de pedigree e de marcadores microssatélites.

\section{MATERIAL E MÉTODOS}

Oito cultivares de trigo foram utilizadas como genitoras: 'CD 104' (PFAU'S"/IAPAR 17), 'CD 105' (PFAU”'S”/2*OCEPAR 14//IAPAR 41), 'CD 108' (TAM 200/TURACO), 'CD 0542' (CD 104/ORL 95282), 'CD 0545' (CD 104/BRS 229), 'CD 0567' (RUBI/CD 105), 'CD 0649' (CEP29/CD 2009)e ‘CD0656' (IPR 85/ORL 95282). Em geral, estas cultivares apresentam ampla adaptação, podendo ser utilizado em vários estados do país, apresentando alto rendimento de grãos, baixa estatura de planta, resistência ao acamamento, tolerância ao calor, tolerância à seca e alta qualidade industrial (FRANCO \& MARCHIORO, 2006).

$\mathrm{O}$ experimento de avaliação dialélica foi delineado em blocos casualizados, com duas repetições, e instalado em 2008 em Palotina-PR. Adotou-se o espaçamento de $0,2 \mathrm{~m}$ entre linhas e entre plantas. Cada linha foi constituída por seis plantas. A cultivar CD 105 foi utilizada como bordadura. As características avaliadas foram ciclo (CIC, da emergência ao espigamento), número de afilhos (NAP) e de espigas por planta (NEP), tamanho de espiga (TE), número de grãos por espiga (NGE), peso de grãos por espiga (PGE), produção de grãos por planta (PP) e peso de mil grãos (PMG).

Os dados experimentais foram avaliados pelo emprego do método quatro proposto por GRIFFING (1956). Para a análise de agrupamento a partir dos dados genealógicos, os coeficientes de parentesco (COP) estimados segundo o método de MALÉCOT (1948) foram convertidos em distâncias (D), tal que D=1COP. Os genótipos foram então agrupados pelo método Unweighted Pair Group Method Using Arithmetic Averages (UPGMA) (SOKAL \& MICHENER, 1958), gerando um dendrograma.

A análise com marcadores microssatélites foi realizada segundo o protocolo descrito por McDONALD et al. (1994), e realizada com base em 26 primers polimórficos, discriminados de acordo com o banco de dados GrainGenes (http:// wheat.pw.usda.gov), da seguinte forma: DuPw115 (5B; 14.6), DuPw167 (6A; 161.2), Wmc41 (2D; 180.5); Wmc41 (2D; 97), Xbarc59 (5B; 121.7), Xbarc113 (6A; 66.1), Xbarc117(5A; 18.8), Xbarc146(6B; 82.1), Xbarc170(4A; 47.6), Xbarc197 (3A; 77.3), Xbarc198 (6B; 31.9), Xbarc297 (2D; 10.7), Xbarc343 (4A; 52.8), Xbarc353.2 (2A; 88.3), Xgwm5 (3A; 50), Xgwm71 (2A; 75.6), DuPw217 (-; -), Xgwm133 (6B; 31.6), Xgwm160 (4A; 77.1), Xgwm161 (3D; 15.7), Xgwm213 (5B; 32.5), Xgwm247 (3A; 117), Xgwm247 (3B; 101), Xgwm285 (3B; 65.3), Xgwm372(2A; 92.1), Xgwm397 (4A; 41.3), Xgwm469 (6D; 20.6) eXgwm499 (5B; 45.6).

O cálculo da distância genética entre dois genótipos (I e J) foi estimado de acordo com YAO (2007), a partir da expressão $\mathrm{D}_{\mathrm{ij}}=1-\mathrm{GS}$, na qual o índice de similaridade genética (GS) foi obtido pelo coeficiente de NEI \& LI (1979), GS=2[( $\left.\left.\mathrm{N}_{\mathrm{ij}}\right) /\left(\mathrm{N}_{\mathrm{i}}+\mathrm{N}_{\mathrm{j}}\right)\right]$, onde $\mathrm{N}_{\mathrm{ij}}=\mathrm{n}^{\mathrm{o}} \mathrm{de}$ alelos comuns a ambos os genótipos para cada primer, enquanto $\mathrm{N}$ e $\mathrm{N}$ representaram o número total de alelos SSR no i-ésímo e noj-ésimo genótipo, respectivamente. Os dados da matriz de distâncias foram utilizados para o agrupamento dos genótipos pelo método UPGMA, sendo gerado outro dendrograma. Por último, as distâncias genéticas foram submetidas ao método de otimização de Tocher (RAO, 1952), com o emprego do programa GENES (CRUZ, 2001).

\section{RESULTADOS E DISCUSSÃO}

Os efeitos de capacidade geral de combinação (CGC) foram significativos para todos os caracteres, exceto para a produção de grãos por planta, indicando diferenças no valor médio dos gametas de cada parental (Tabela 1). Os valores de CGC dos parentais indicam o grande potencial de CD 108, CD 0542 e CD 104 (Tabela 2). A variedade CD 108 apresentou grande CGC para precocidade, afilhamento e prolificidade. CD 0542 teve alta CGC para a número de afilhos e de espigas por planta, grãos por espiga e produção de grãos por planta. No entanto, CD 0542 evidenciou uma tendência de gerar híbridos mais 
Tabela 1 - Análises de variância de diferentes caracteres avaliados no experimento dialélico de trigo conduzido em 2008 em Palotina-PR, envolvendo os parentais CD 104, CD 105, CD 108, CD 0542, CD 0545, CD 0567, CD 0649 e CD 0656.

\begin{tabular}{|c|c|c|c|c|}
\hline \multirow{2}{*}{ Caráter ${ }^{(1)}$} & & $\mathrm{QM}^{(2)}$ & & \multirow{2}{*}{ Média } \\
\hline & CGC & CEC & Resíduo & \\
\hline$\overline{\mathrm{CIC}}$ & $25,470238 * *$ & $8,209525^{*}$ & 2,393525 & 65,732143 \\
\hline NAP & $21,785714 *$ & $10,376710^{\mathrm{ns}}$ & 6,530159 & 15,928571 \\
\hline NEP & $22,343810 * *$ & $4,839525^{\mathrm{ns}}$ & 3,971237 & 13,092857 \\
\hline $\mathrm{TE}$ & $3,320714 * *$ & $0,449860 *$ & 0,180493 & 9,632143 \\
\hline NGE & $210,691190^{* *}$ & $46,910765^{\mathrm{ns}}$ & 25,236059 & 44,639286 \\
\hline PGE & $0,195121^{* *}$ & $0,068910^{\mathrm{ns}}$ & 0,043581 & 1,321786 \\
\hline PP & $29,503476^{\text {ns }}$ & $20,472625^{\mathrm{ns}}$ & 16,338578 & 13,170000 \\
\hline PMG & $65,999055^{* *}$ & $5,134560^{\mathrm{ns}}$ & 5,450704 & 29,595357 \\
\hline
\end{tabular}

${ }^{(1)}$ CIC: ciclo, NAP: número de afilhos por planta, NEP: número de espigas por planta, TE: tamanho da espiga, NGE: número de grãos por espiga, PGE: peso de grãos por espiga, PP: produção por planta e PMG: peso de mil grãos. ${ }^{(2)} \mathrm{ns}=$ efeito não significativo; * $=$ efeito significativo a $5 \%$ de probabilidade; $* *$ = efeito significativo a $1 \%$ de probabilidade.

tardios. Por último, CD 104 destacou-se em CGC para tamanho, número de grãos e peso de grãos por espiga, em conformidade com as características já relatadas por FRANCO (2009).

Os efeitos da capacidade específica de combinação (CEC) para ciclo e tamanho de espigas foram significativos (Tabela 3). A alta CEC do híbrido CD 104 x CD 0542 indica que efeitos não aditivos aumentaram ainda mais o ciclo tardio que seria de se esperar com base na alta CGC de seus genitores. Por outro lado, a CEC negativa de CD 0542 x CD 108 denota uma precocidade que contraria o esperado com base na CGC alta e positiva de seus pais. Com relação ao tamanho de espiga, a combinação de CD 104 (CGC positiva) com CD 108 (CGC negativa) resultou em espigas relativamente grandes. $\mathrm{O}$ cruzamento de $\mathrm{CD}$ 0545 (CGC negativa) com CD 0656 (CGC positiva) também resultou em espigas relativamente grandes, sugerindo a manifestação de dominância no controle desse caráter. Por outro lado, efeitos não aditivos permitiram que nem sempre os híbridos provenientes de parentais com alta CGC fossem satisfatórios. Este foi o caso de CD 104 x CD 0656, material com CEC negativa de alta magnitude.

Houve maior frequência de valores extremos (positivos ou negativos) de CEC nos híbridos formados a partir de CD 0542 e CD 104. Essa constatação é importante porque, quando tais genitores forem

Tabela 2 - Estimativas da capacidade geral de combinação $\left(\mathrm{g}_{\mathrm{i}}\right)$ das cultivares parentais de trigo avaliadas no experimento dialélico conduzido em 2008 em Palotina-PR.

\begin{tabular}{|c|c|c|c|c|c|c|c|c|}
\hline \multirow{2}{*}{ Parental } & \multicolumn{8}{|c|}{ - 20 aracteres avaliados ${ }^{(1)}$} \\
\hline & CIC & NAP & NEP & $\mathrm{TE}$ & NGE & PGE & PP & PMG \\
\hline CD 104 & 1,8125 & $-0,0667$ & $-0,0250$ & 0,5958 & 5,3542 & 0,1463 & 0,9483 & $-0,3896$ \\
\hline CD 105 & 0,0625 & $-0,5333$ & 0,2750 & 0,3292 & 0,5708 & 0,1146 & 0,7100 & 2,3630 \\
\hline CD 108 & $-1,4375$ & 1,8000 & 1,9583 & $-0,2708$ & $-2,4625$ & $-0,0304$ & 1,2350 & 0,9421 \\
\hline CD 0542 & 2,2292 & 1,9833 & 0,8917 & 0,2793 & 4,7708 & $-0,0404$ & 1,7683 & $-3,9596$ \\
\hline CD 0545 & $-1,8542$ & 0,3833 & 0,6250 & $-1,0042$ & $-5,1125$ & $-0,1921$ & $-0,4783$ & $-1,1846$ \\
\hline CD 0567 & $-0,0208$ & $-0,4333$ & 0,2417 & $-0,3042$ & $-2,8458$ & $-0,1521$ & $-0,5483$ & $-1,6346$ \\
\hline CD 0649 & 0,2292 & $-1,6000$ & $-1,9083$ & $-0,0875$ & 3,7875 & 0,1263 & $-0,4000$ & 0,4054 \\
\hline CD 0656 & $-1,0208$ & $-1,5333$ & $-2,0583$ & 0,4625 & $-4,0625$ & 0,0279 & $-3,2350$ & 3,4588 \\
\hline $\mathrm{DP}(\mathrm{gi})^{(2)}$ & 0,4178 & 0,6900 & 0,5381 & 0,1147 & 1,3565 & 0,0564 & 1,0915 & 0,6304 \\
\hline $\mathrm{DP}(\mathrm{gi}-\mathrm{gj})^{(3)}$ & 0,6316 & 1,0432 & 0,8136 & 0,1734 & 2,0509 & 0,0852 & 1,6502 & 0,9531 \\
\hline
\end{tabular}

${ }^{(1)}$ CIC: ciclo, NAP: número de afilhos por planta, NEP: número de espigas por planta, TE: tamanho da espiga, NGE: número de grãos por espiga, PGE: peso de grãos por espiga, PP: produção por planta e PMG: peso de mil grãos. ${ }^{(2)}$ Desvio padrão da estimativa $\mathrm{g}_{\mathrm{i} \cdot} \cdot{ }^{(3)}$ Desvio padrão da diferença entre $g_{i}$ e $g_{j}$.

Ciência Rural, v.41, n.10, out, 2011. 
Tabela 3 - Estimativas de capacidade específica de combinação $\left(\mathrm{s}_{\mathrm{ij}}\right)$ para ciclo (acima da diagonal) e tamanho de espiga (abaixo da diagonal) dos híbridos de trigo procedentes do dialelo conduzido em 2008 em Palotina-PR.

\begin{tabular}{llllllll}
\hline Parentais & CD 104 & CD 105 & CD 108 & CD 0542 & CD 0545 & CD 0567 & CD 0649 \\
\hline CD 104 & - & $-0,6071$ & 1,3929 & 3,2262 & $-1,6905$ & $-2,0238$ & $-0,2738$ \\
CD 105 & 0,0571 & - & $-0,8571$ & 2,4762 & $-0,9405$ & $-1,2738$ & 0,9762 \\
CD 108 & 0,9429 & $-0,4909$ & - & $-3,0238$ & 1,0596 & 2,2262 & $-1,5238$ \\
CD 0542 & 0,1929 & 0,2596 & $-0,3404$ & - & $-2,1071$ & $-2,9405$ & 0,8095 \\
CD 0545 & $-0,6238$ & 0,5429 & 0,0429 & $-0,2071$ & - & 2,1429 & 1,3929 \\
CD 0567 & $-0,0238$ & 0,0429 & 0,3429 & $-0,6071$ & $-0,0238$ & - & 0,14262 \\
CD 0649 & 0,3596 & $-0,2738$ & $-0,4738$ & 0,5762 & $-0,3404$ & 0,1596 & - \\
CD 0656 & $-0,7904$ & $-0,0238$ & $-0,0238$ & 0,1262 & 0,6096 & 0,1096 & $-0,0071$ \\
\hline
\end{tabular}

utilizados em cruzamentos, a seleção seria mais oportuna em gerações avançadas, dada a redução dos efeitos de dominância e epistasia.

As distâncias genéticas baseadas em marcadores moleculares foram utilizadas para agrupar os genótipos pelo método UPGMA (Figura 1A). O ponto de corte foi definido em função do número de grupos indicado pela análise de otimização de Tocher (RAO, 1952; MARCHIORO et al., 2003; KARASAWA et al., 2005; SOUZA et al., 2005; SILVA et al., 2009). Quatro

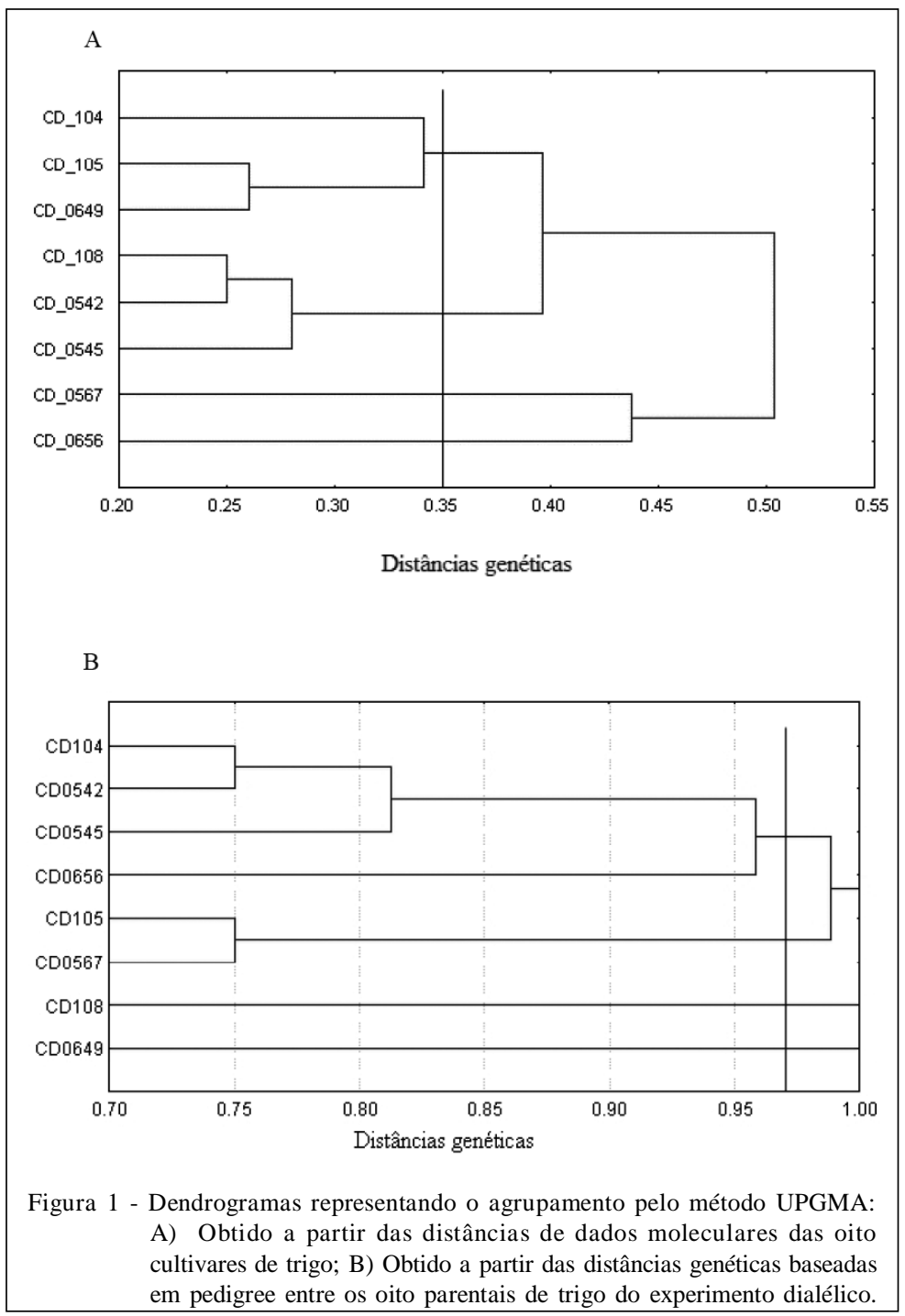

Ciência Rural, v.41, n.10, out, 2011. 
grupos foram caracterizados com o ponto de corte na posição 0,35: CD 104, CD 105 e CD 0649 no primeiro grupo; CD 108 e CD 0542 e CD 0545, no segundo; CD 0567 no terceiro; e CD 0656, no quarto.

Os híbridos entre cultivares de grupos distintos deveriam ser, a priori, mais heterozigóticos que os demais. É oportuno, portanto, verificar se os cruzamentos com alta CEC correspondem às maiores expectativas de heterozigose. No caso do tamanho de espigas, os maiores valores positivos de $s_{\mathrm{ij}}$ foram detectados em cruzamentos com parentais de grupos diferentes (CD 108 x CD 104 e CD 0656 x CD 0545). Para ciclo, os maiores valores positivos de CEC também corresponderam aos cruzamentos entre parentais de grupos diferentes (CD 104 x CD 0542; CD 105 x CD 0542; CD 108 x CD 0567 e CD 0545 x CD 0567). Em geral, foram contabilizados 12 cruzamentos com cultivares participantes de grupos distintos, e um único cruzamento com cultivares do mesmo grupo. Pode ser observada uma tendência de maior heterozigose e de efeitos de CEC em cruzamentos com cultivares de grupos diferentes (Tabela 3).

Tomando-se a média das distâncias como ponto de corte, verificou-se a formação de 4 grupos (Figura 1B). No caso dos dois últimos clusters (CD 108 no terceiro e CD 0649 no quarto), os parentais se posicionam mais distantes dos demais porque não possuem nenhuma relação de parentesco entre si e com nenhum parental avaliado.

Os dados de genealogia podem refletir as distâncias relativas entre os parentais, bem como seus respectivos níveis de agrupamento. Por outro lado, o uso dos marcadores moleculares é uma ferramenta importante para a definição das distâncias e dos agrupamentos, especialmente se forem escassas as informações de pedigree. Pela comparação das Figuras $1 \mathrm{~A}$ e 1B, nota-se que a coincidência dos genótipos dos grupos não foi perfeita. Resultados semelhantes de ausência de correlação entre as distâncias genéticas obtidas por diversos procedimentos foram também verificados por diversos autores (BERED et al., 2001; MÁRIC et al., 2004; VIEIRA et al., 2005; BERTAN et al., 2007; FONSECA et al., 2007).

As distâncias por pedigree refletem a probabilidade de os parentais compartilharem os mesmo alelos (coancestralidade). Além disso, as estimativas das distâncias obtidas por pedigree podem ser incorretas pela não observância da ausência de seleção (ALMANZA-PINZÓN et al., 2003), pelo desconhecimento dos ancestrais mais remotos de cada cultivar e pela falta de genealogia comum entre os genótipos testados (BERTAN et al., 2007). Como as distâncias estimadas pelos microssatélites medem o compartilhamento efetivo dos segmentos de DNA, a informação gerada é mais consistente do que uma estimativa de probabilidades. Tais considerações sugerem que, neste trabalho, as distâncias quantificadas pelo uso dos marcadores moleculares devam refletir melhor as relações entre as cultivares de trigo. No entanto, a análise individual e a combinação de diferentes medidas de distância pode ser mais recomendável à estimação do nível de variabilidade e à predição de desempenho de progênies do que o emprego de uma única metodologia. (BERED et al., 2001; VIEIRA et al., 2007).

\section{CONCLUSÃO}

As cultivares 'CD 108', 'CD 0542' e 'CD 104' apresentam alta CGC e maior potencial de contribuição ao programa de melhoramento. Há concordância entre os resultados de campo e os resultados moleculares, com efeitos mais pronunciados da CEC nos cruzamentos entre genótipos de grupos diferentes, provavelmente mais heterozigóticos.

A menor consistência das distâncias calculadas por pedigree é provavelmente responsável pela falta de correlação entre as distâncias genéticas obtidas a partir dos dois procedimentos $(\mathrm{r}=0,04)$, considerando os genitores analisados.

\section{REFERÊNCIAS}

ALMANZA-PINZÓN, M.I. et al. Comparison of molecular markers and coefficients of parentage for the analysis of genetic diversity among spring bread wheat accessions. Euphytica, v.130, p.77-86, 2003. Disponível em: <http:// www.springerlink.com/content/h01015q04h614532/>. Acesso em: 23 nov. 2007. doi: 10.1023/A:1022310014075.

BERED, F. et al. Genetic variability in common wheat based on morphological traits, coefficients of parentage and RAPDs. Journal of New Seeds, v.3, p.73-87, 2001. Disponível em: <http://www.tandfonline.com/doi/abs/10.1300/ J153v03n02_05\#preview>. Acesso em: 11 ago. 2008. doi: 10.1300/J153V03N02_05.

BERTAN, I. et al. Genetic variability in wheat measured by pedigree and morphological distance. Scientia Agraria, v.8, p.67-74, 2007. Disponível em: <http://dialnet.unirioja.es/ servlet/articulo? codigo=2907911>. Acesso em 26 jun. 2008. ISSN 1983-2443.

CAIERÃO, E. et al. Análise da adaptabilidade e da estabilidade de genótipos de trigo como ferramenta auxiliar na recomendação de novas cultivares. Ciência Rural, v.36, p.1112-1117, 2006. Disponível em: <http://www.scielo.br/scielo.php?script=sci_arttext\&pid=S010384782006000400011>. Acesso em: 13 mai. 2008. doi: 10.1590/S010384782006000400011 .

CRUZ, C.D. Programa genes. Aplicativo computacional em genética e estatística. Viçosa: UFV, 2001. 422p. 
CRUZ, C.D. et al. Modelos biométricos aplicados ao melhoramento genético. Viçosa: UFV, 2004. 480p.

FONSECA, A.F.A. et al. Divergência genética em café conilon. Pesquisa Agropecuária Brasileira, v.41, p. 599 605, 2006. Disponível em: <http://www.scielo.br/ scielo.php? script $=\mathrm{sci}_{\text {_ }}$ art text \& pid $=\mathrm{S} 0100$ $204 X 2006000400008 \& \mathrm{nrm}=\mathrm{isso} \& \mathrm{t} \operatorname{lng}=\mathrm{pt}>$. Acesso em: 03 jun. 2008. doi: 10.1590/S0100-204X2006000400007.

FONSECA, D.A.R. et al. Comparação entre técnicas de estimativa de distância genética em trigos. In: CONGRESSO DE INICIAÇÃO CIENTÍFICA, 16., 2007, Pelotas, RS. Anais... Pelotas: Universidade Federal de Pelotas, 2007. Disponível em: 〈http://www.ufpel.edu.br/xvicic/cd/pdf/CA/CA_00212.pdf > Acesso em: 13 ago. 2008.

FRANCO, F.A. Tolerância à germinação na espiga em cultivares de trigo colhido na maturação fisiológica. Ciência Rural, v.39, p.2396-2401, 2009. Disponível em: <http:// ww w. s c i e lo.br/s c i e 1 o.ph p ? p id = S 0103 $84782009000900003 \&$ script $=$ sci_abstract $\&$ tlng $=$ pt $>$. Acesso em: 20 dez. 2009. doi: 10.1590/S0103-84782009005000212.

FRANCO, F.A.; MARCHIORO, V.S. Novos cultivares de trigo da COODETEC. Disponível em: http://www2.coodetec.com.br/ coodetec/listProdutos.action?culturaId=4. Acesso em: 29 abr. 2008 .

FRANCO, J. et al. A method for combining molecular markers and phenotypic attributes for classifying plant genotypes. Theoretical and Applied Genetics, v.103, p.944-952, 2001. Disponível em: <http://www.mendeley.com/research/a-methodfor-combining-molecular-markers-and-phenotypic-attributesfor-classifying-plant-genotypes-1/>. Acesso em: 27 de ago. 2008. doi: 10.1007/S001220100641.

GANDIN, C.L. et al. Effects of the combining ability of different genotypes on agronomically important traits in wheat. Brazilian Journal of Genetics, v.6, p.473-490, 1983. Disponível em: <http://web2.sbg.org.br/gmb/edicoesanteriores/ v06n3/pdf/a09v06n3.pdf>. Acesso em: 29 de ago. 2008.

GRIFFING, B. Concept of general and specific combining ability in relation to diallel crossing systems. Australian Journal of Biological Sciences, v.9, p.463-493, 1956. Disponível em: <http:/ /www.publish.csiro.au/?act=view_file\&file_id=BI9560463.pdf $>$. Acesso em 28 abr. 2008. doi: 10.1071/BI9560463.

KARASAWA, M. et al. Aplicação de métodos de agrupamento na quantificação da divergência genética entre acessos de tomateiro. Horticultura Brasileira, v.23, p.1000-1005, 2005. Disponível em: <http://www.scielo.br/scielo.php?pid=S0102$05362005000400028 \&$ script $=$ sci_arttext $>$. Acesso em: 11 de mai de 2008. doi: 10.1590/S0102-05362005000400027.

MALÉCOT, G. Les mathématiques de l'hérédité. Paris: Masson, 1948. 63p.

MARCHIORO, V.S. et al. Dissimilaridade genética entre genótipos de aveia. Ciência e Agrotecnologia, v.27, p.285-294, 2003. Disponível em: <http://www.scielo.br/scielo.php?pid=S1413- 70542003000200006\&script=sci_abstract\&tlng=pt > Acesso em: 29 de jan. 2008. doi: 10.1590/S1413-70542003000200006.

MÁRIC, S. et al. Genetic diversity os hexaploid wheat cultivars estimated by RAPD markers, morphological traits and coefficients of parentage. Plant Breeding, v.123, p.366369, 2004. Disponível em: <http://onlinelibrary.wiley.com/doi/ 10.1111/j.1439-0523.2004.00956.x/abstract>. Acesso em: 11 de jan. 2009. doi: 10.1111/J.1439-0523.2004.00956.X.

McDONALD, M.D. et al. DNA extraction from dry seeds for RAPD analysis in varietal identification studies. Seed Science and Technology, v.22, p.171-176, 1994. Disponível em: $\langle$ http://cat.inist.fr/?aModele $=$ afficheN\&cpsidt $=4176870\rangle$. Acesso em 13 jan. 2008. INIST: 1663, 35400004632601.0190.

NEI, M.; LI, W.H. Mathematical model for studying genetic variation in terms of restriction endonucleases. Proceedings of the National Academy of Sciences, v.76, p.5269-5273, 1979. Disponível em: <http://www.pnas.org/content/76/10/ 5269>. Acesso em: 02 de set. 2008. doi: PNAS 5269-5273.

RAO, R.C. Advanced statistical methods in biometric research. New York: John Wiley, 1952. 390p.

SILVA, T.A. et al. Genetic divergence in popcorn genotypes using microsatellites in bulk genomic DNA. Crop Breeding and Applied Biotechnology, v.9, p.31-36, 2009. Disponível em: <http://www.sbmp.org.br/cbab/siscbab/uploads/c812949154f5-e00c.pdf $>$. Acesso em: 22 jul. 2009.

SOKAL, R.R.; MICHENER, C.D. A statistical method for evaluating systematic relationships. University of Kansas Scientific Bulletin, v.38, p.1409-1438, 1958. Disponível em: 〈http://www.citeulike.org/user/druvus/article/1327877>. Acesso em: 12 de mai. 2009. CITEULIKE: 1327877.

SOUZA, F.F. et al. Divergência genética em linhagens de melancia. Horticultura Brasileira, v.23, p.179-183, 2005. Disponível em: $<$ http://www.scielo.br/scielo.php?script=sci_arttext\&pid=S010205362005000200003>. Acesso em: 12 de mar. 2008. doi: 10.1590/ S0102-0536200500020003.

VIEIRA, E.A. et al. Comparação entre medidas de distância genealógica, morfológica e molecular em aveia em experimentos com e sem a aplicação de fungicida. Bragantia, v.64, p.51-60, 2005. Disponível em: <http://www.scielo.br/scielo.php?pid=S0006$87052005000100006 \&$ script $=$ sci_abstract $\&$ tlng $=$ pt $>$. Acesso em: 11 de ago. 2008. doi: 10.1590/S0006-87052005000100005.

VIEIRA, E.A. et al. Association between genetic distances in wheat ( Triticum aestivum L.) as estimated by AFLP and morphological markers. Genetics and Molecular Biology, v.30, p.392-399, 2007. Disponível em: <http://www.scielo.br/scielo.php?pid=S141547572007000300016\&script=sci_arttext $>$. Acesso em: 17 de jan. 2008. doi: 10.1590/S1415-47572007000300015.

YAO, Q. et al. Genetic diversity of maize (Zea mays L.) landraces from Southwest China based on SSR Data. Journal of Genetics and Genomics, v.34, p.851-860, 2007. Disponível em: <http://www.sciencedirect.com/science/article/ pii/S1673852707600964>. Acesso em: 11 de fev. 2008. doi: 10.1016/S1673-8527(07)60096-4. 